\title{
Effect of UVB light on vitamin D status in piglets and sows
}

Stricker Jakobsen, Sine; Nielsen, Jens Peter; Jakobsen, Jette

Published in:

The Journal of Steroid Biochemistry and Molecular Biology

Link to article, DOI:

10.1016/j.jsbmb.2020.105637

Publication date:

2020

Document Version

Peer reviewed version

Link back to DTU Orbit

Citation (APA):

Stricker Jakobsen, S., Nielsen, J. P., \& Jakobsen, J. (2020). Effect of UVB light on vitamin D status in piglets and sows. The Journal of Steroid Biochemistry and Molecular Biology, 200, [105637].

https://doi.org/10.1016/j.jsbmb.2020.105637

\section{General rights}

Copyright and moral rights for the publications made accessible in the public portal are retained by the authors and/or other copyright owners and it is a condition of accessing publications that users recognise and abide by the legal requirements associated with these rights.

- Users may download and print one copy of any publication from the public portal for the purpose of private study or research.

- You may not further distribute the material or use it for any profit-making activity or commercial gain

- You may freely distribute the URL identifying the publication in the public portal

If you believe that this document breaches copyright please contact us providing details, and we will remove access to the work immediately and investigate your claim 


\section{Journal Pre-proof}

Effect of UVB light on vitamin D status in piglets and sows

Sine Stricker Jakobsen (Methodology)

(Investigation)<ce:contributor-role>Formal Analysis) (Writing -

original draft), Jens Peter Nielsen (Conceptualization)

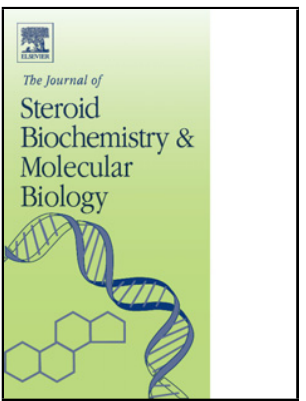

(Methodology) (Writing - review and editing) (Supervision) (Funding

acquisition), Jette Jakobsen (Conceptualization) (Methodology)

(Writing - review and editing) (Supervision) (Project administration)

(Funding acquisition)

PII:

S0960-0760(19)30558-8

DOI:

https://doi.org/10.1016/j.jsbmb.2020.105637

Reference:

SBMB 105637

To appear in:

Journal of Steroid Biochemistry and Molecular Biology

Received Date:

13 September 2019

Revised Date:

28 January 2020

Accepted Date:

18 February 2020

Please cite this article as: Stricker Jakobsen S, Nielsen JP, Jakobsen J, Effect of UVB light on vitamin D status in piglets and sows, Journal of Steroid Biochemistry and Molecular Biology (2020), doi: https://doi.org/10.1016/j.jsbmb.2020.105637 
This is a PDF file of an article that has undergone enhancements after acceptance, such as the addition of a cover page and metadata, and formatting for readability, but it is not yet the definitive version of record. This version will undergo additional copyediting, typesetting and review before it is published in its final form, but we are providing this version to give early visibility of the article. Please note that, during the production process, errors may be discovered which could affect the content, and all legal disclaimers that apply to the journal pertain.

(C) 2019 Published by Elsevier. 


\title{
Effect of UVB light on vitamin D status in piglets and sows
}

\author{
Sine Stricker Jakobsen ${ }^{\mathrm{a}}$, Jens Peter Nielsen ${ }^{\mathrm{a}}$, Jette Jakobsen ${ }^{\mathrm{b}}$ \\ ${ }^{a}$ University of Copenhagen, Department of Veterinary and Animal Sciences, Grønnegårdsvej 2, 1870 \\ Frederiksberg C, Denmark \\ ${ }^{b}$ Technical University of Denmark, National Food Institute, Kemitorvet, 2800 Kgs. Lyngby
}

\section{Corresponding author}

Sine Stricker Jakobsen, Sine.stricker.jakobsen@sund.ku.dk

Highlights

- Piglets was born with very low levels of vitamin $D<2 \mathrm{ng} / \mathrm{ml}$

- UVB light significantly improved vitamin $D$ status in piglets and sows

- Improving vitamin $D$ status did not increase the weaning weight of piglets

- No adverse effects were observed when exposing piglets to UVB light up to 1 SED

\begin{abstract}
Piglets are born with very low levels of vitamin D. Feed is the only source of vitamin D for pigs kept indoors, and the levels in feed are restricted by European legislation. We aimed to study the effect of lamps releasing ultraviolet type B (UVB) light on the vitamin D status (serum 25-hydroxyvitamin D) in sows and piglets in a Danish indoor herd.

A randomized trial with a parallel group design was initiated with two groups receiving a daily UVB-dose of maximum 0.7 standard erythema dose (SED) or $1 \mathrm{SED}$, in addition to a control group. The three groups included in the study consisted of 15 sows and their 195 offspring. Blood samples were taken from the piglets and sows on day 1,12 , and 24 . Results showed no difference between the groups in serum levels of $25(\mathrm{OH}) \mathrm{D}_{3}$ or vitamin $\mathrm{D}_{3}$ on day 1 , with the mean $( \pm \mathrm{SD})$ for piglets being $0.96 \pm 0.26 \mathrm{ng} / \mathrm{mL}$ and $0.06 \pm 0.04 \mathrm{ng} / \mathrm{mL}$, respectively. For sows, the values were $16 \pm 3 \mathrm{ng} / \mathrm{mL} 25(\mathrm{OH}) \mathrm{D}_{3}$ and $3 \pm 0.8 \mathrm{ng} / \mathrm{mL}$ vitamin $\mathrm{D}_{3}$ on day 1 . A
\end{abstract}


significant difference $(\mathrm{p}<0.001)$ in serum $25(\mathrm{OH}) \mathrm{D}_{3}$ between the groups receiving UVB light and the control group was observed on both day 12 and day 24 . On day 24 , the piglet control group had $5.5 \pm 2 \mathrm{ng} / \mathrm{mL} 25(\mathrm{OH}) \mathrm{D}_{3}$ and $0.4 \pm 0.2 \mathrm{ng} / \mathrm{mL}$ vitamin $\mathrm{D}_{3}$. For the UVB groups, the values were $21.6 \pm 10 . \mathrm{ng} / \mathrm{mL} 25(\mathrm{OH}) \mathrm{D}_{3}$ and $8.3 \pm 2.5$ $\mathrm{ng} / \mathrm{mL}$ vitamin $\mathrm{D}_{3}$ for the 0.7 SED group and $19.5 \pm 6.0 \mathrm{ng} / \mathrm{mL} 25(\mathrm{OH}) \mathrm{D}_{3}$ and $7.6 \pm 3.4 \mathrm{ng} / \mathrm{mL}$ vitamin $\mathrm{D}_{3}$ for the $1 \mathrm{SED}$ group. For the sows, the values were $25.6 \pm 5.5 \mathrm{ng} / \mathrm{mL} 25(\mathrm{OH}) \mathrm{D}_{3}$ and $6.6 \pm 1.2 \mathrm{ng} / \mathrm{mL}$ vitamin $\mathrm{D}_{3}$ for the control group, $66.7 \pm 13.5 \mathrm{ng} / \mathrm{mL} 25(\mathrm{OH}) \mathrm{D}_{3}$ and $21.3 \pm 2.9 \mathrm{ng} / \mathrm{mL}$ vitamin $\mathrm{D}_{3}$ for $0.7 \mathrm{SED}$ group and $67 \pm 15$ $\mathrm{ng} / \mathrm{mL} 25(\mathrm{OH}) \mathrm{D}_{3}$ and $25 \pm 5 \mathrm{ng} / \mathrm{mL}$ vitamin $\mathrm{D}_{3}$ for the $1 \mathrm{SED}$. No significant difference was found between the two UVB groups for either piglets or sows. The use of lamps releasing UVB light is therefore suggested to be an efficient way to improve the vitamin D status of both sows and piglets.

\section{Keywords: Vitamin D, UVB, pigs, piglets, 25-hydroxyvitamin $\mathrm{D}_{3}$}

\section{Introduction}

In humans, vitamin D deficiency is recognized worldwide as a problem[1,2]. The natural inducer of vitamin D production is the UVB wavelengths from sunlight $(290-315 \mathrm{~nm})$ that transform 7-dehydrocholesterol to previtamin $\mathrm{D}_{3}$, which, following a temperature-dependent process, converts to vitamin $\mathrm{D}_{3}$ in the skin. If UVB exposure is not sufficient to produce adequate vitamin $\mathrm{D}$, humans must rely on vitamin $\mathrm{D}$ in the diet. This is also the case for most indoor housed terrestrial vertebrates. Danish pig production uses mainly indoor facilities, where the pigs have no access to outdoor facilities and thereby no access to sunlight. The Danish recommendations for vitamin $\mathrm{D}$ for pigs relates to the amount in feed, while the levels in the serum are unknown. This raises the question of whether Danish pigs have a sufficient vitamin D status, which is measured as 25-hydroxyvitamin D in serum (S-25OHD).

European legislation allows the addition of up to 2,000 I.U./kg (50 $\mu \mathrm{g} / \mathrm{kg})$ of vitamin D i.e. vitamin D3, vitamin D2 or 25-hydroxyvitamin D3 to pig feed[3, 4]. The recommendations in Denmark are between 400 and 800 IU vitamin D per kg dry matter of diet to be added to the feed depending on the age of the pig[5]. To date, no recommendations relating to $\mathrm{S}-25 \mathrm{OHD}$ concentrations in pigs have been established. It is therefore difficult to 
determine whether and when the vitamin D status of a pig is sufficient, insufficient or deficient. If the human definitions are applied, a level of $20 \mathrm{ng} / \mathrm{mL}$ would be considered adequate, a level of $12-20 \mathrm{ng} / \mathrm{mL}$ would be considered insufficient, and a level below $12 \mathrm{ng} / \mathrm{mL}$ would be considered deficient[6]. Since we do not know whether or not the vitamin D status of production pigs is optimal, it could be speculated that increasing vitamin D levels could improve the general health and welfare of pigs kept indoors.

Vitamin D is used for many purposes in bodies functioning under normal conditions. The best-described vitamin D deficiency condition in pigs is rickets, which causes malformation of bone tissue, but, like in humans, vitamin $\mathrm{D}$ status also has an effect on immune functions[7], growth[8,9] and reproductive performance[10] among others.

When optimizing the vitamin D status of pigs via feed, there is a risk of both insufficient supply as well as toxicity. Vitamin D poisoning in pigs has been documented in experimental settings as well as being described in case studies. Vitamin D poisoning can lead to anorexia, vomiting, calcification of soft tissue such as the lungs, heart and kidneys, weight loss or reduced growth, lethargy, polyuria polydipsia and eventually death[11-14].

Investigation of health effect of feeding pregnant sows maximal level i.e. $2000 \mathrm{IU}$ vitamin $\mathrm{D} / \mathrm{kg}$, as vitamin $\mathrm{D}_{3}$ or $25 \mathrm{OHD}_{3}$ showed a significant increased birthweight in the $25 \mathrm{OHD}_{3}$ group, but no difference of weight at weaning [15]. Oral administration of vitamin $\mathrm{D}_{3}$ for piglets at 2 days of age as a single dose of 40,000 IU vitamin $\mathrm{D}_{3}$ resulted in an increased weight at weaning [8]. This could indicate that both sows and piglets may suffer from vitamin D insufficiency.

UVB light covers the wavelengths between $280 \mathrm{~nm}$ and $320 \mathrm{~nm}$. Vitamin D production for both humans and animals occurs at wavelengths below $315 \mathrm{~nm}$, with its peak at around 295-300 nm nm[16]. Vitamin D production in response to UVB light cannot reach toxic levels due to the negative feedback system where previtamin $\mathrm{D}_{3}$ continuously exposed to UVB light will convert in to lumisterol and tachysterol[17,18]. If UVBderived vitamin $\mathrm{D}_{3}$ reaches a steady state in pigs, this level could be used as an optimal reference level. However, no steady state was achieved in the pigs with daily UVB exposure over 28 days[19].

The unit standard erythema dose (SED) takes into account the irradiant dose and the level of erythema on human skin, and $1 \mathrm{SED}$ is equivalent to $100 \mathrm{~J} / \mathrm{m}^{2}$. It is a fixed measure that is not dependent on skin type, and 
is easily comparable. In Denmark at $55^{\circ}$ North 1 SED is equivalent to 10 minutes of sun exposure at zenith in summertime [20].

The aim of the present study was to investigate the effect of a daily UVB-dose on vitamin D levels in sows and their piglets until weaning.

\section{Materials and Methods}

The Danish Animal Experimentation Council approved the study. A veterinarian inspected the pigs daily.

\subsection{Experimental design}

The study was set up as a randomized parallel study with two treatment groups and a control group. Sample size was based on results from a similar study conducted in slaughterpigs by Barnkob et al.[19]. A required group size of 5 was determined based on an expected standard deviation of 25 , a difference between treatment and control groups of $43 \mathrm{ng} / \mathrm{ml}$, a significance level of 0.05 and a power of $80 \%$.

\subsection{Animals and facilities}

Each group consisted of 5 sows with 13 piglets. The study was conducted over the period $1^{\text {st }}$ to $29^{\text {th }}$ June 2018 in a Danish herd with 1,270 sows and a health declaration of SPF+Myc+Ap2+Ap12. Danavl sows (Danish Landrace X Yorkshire (L/Y)) were mated with Danavl Duroc boars. Healty sows multiparious with expected farrowing dates between $1^{\text {st }}$ and $5^{\text {th }}$ June 2018 were selected for the study. Sows with expected farrowing dates between $1^{\text {st }}$ and $5^{\text {th }}$ June 2018 which belonged to parity 2-5 and showed no clinical signs of illnesses the week prior to farrowing were included. The sows were allocated to one of three groups (by random, using randomized numbers in Microsoft Excel) in the week prior to farrowing. The study began on the day of farrowing and ended on day 24 after farrowing. The sows and piglets were housed in two farrowing rooms each containing 20 identical pens. Each group included sows in both of the rooms to avoid issues with potential differences between the rooms. Calcium hydroxide was used to stain the windows in order to prevent UVB rays entering. Sows and piglets in the control group were placed in pens located at least $2 \mathrm{~m}$ from pens with 
UVB light. Pigs with a birthweight of $900 \mathrm{~g}$ or more which had no health issues at birth were included in order to minimize the loss of piglets during the trial.

Sows were fed a home-mixed liquid diet. Two batches of the liquid feed were analyzed, which showed a content of 4.5 vitamin $\mathrm{D}_{3}$ per $\mathrm{kg}$ and $5.1 \mu \mathrm{g}$ vitamin $\mathrm{D}_{3}$ per $\mathrm{kg}$. The piglets' primary diet consisted of sows milk, which from day 2 were supplemented with up to 0.5 liter of milk per litter per day (Danmilk supreme 1.0 from Agrokorn A/S). From day 7 ad libitum pelleted feed (Danish new wean from Danish Agro a.m.b.a.) was fed to the piglets on the floor. Analyses of the levels of vitamin $\mathrm{D}_{3}$ showed that the aqueous milk supplement contained $12 \mu \mathrm{g}$ vitamin $\mathrm{D}_{3}$ per $\mathrm{kg}$, and the pelleted feed contained $11 \mu \mathrm{g}$ vitamin $\mathrm{D}_{3}$ per $\mathrm{kg}$.

\subsection{UVB exposure}

Piglets and sows in the treatment groups received UVB light in two different doses: 0.7 SED and 1.0 SED, while the control group received no UVB light. Two UVB light tubes were placed over each of the 10 pens containing the sows and piglets receiving a daily dose of UVB light. One tube was hung over the piglets nest (47 $\mathrm{cm}$ to the floor) and one tube was placed above the sow (180-190 $\mathrm{cm}$ to the floor). Pigs were gradually exposed to the UVB light, starting with one hour/day on day 1 (due to technical problems, the UVB exposure for sows started on day 2) up to 6 hours/day from day 8 to day 24. The 6 hours of UVB light was split between two hours in the morning ( 4 am- $6 \mathrm{am})$ and 4 hours in the evening $(6 \mathrm{pm}-10 \mathrm{pm})$. These times were chosen to prevent personnel being present during UVB exposure, and to avoid disturbing the nocturnal rhythm of the pigs. The duration of exposure was chosen to be as long as possible in order to increase the chance of all piglets in the UVB groups receiving a daily dose of UVB light.

\subsubsection{UVB light source}

The UVB lights (Lucky Reptile UV sun T5, 24 W tubes, luckyreptile.com, Germany) in the piglet nests were covered by Plexiglas without UVB filter. A dimmer was attached to the lamp to enable adjustment and ensure that the correct UVB-dose was given to each treatment group. The UVB lamps (Lucky Reptile UV sun T5, $54 \mathrm{~W}$ tubes, luckyreptile.com, Germany) placed above the sows had no cover. For the sows, the UVB light were measured and the height adjusted to establish the correct dose for each treatment group. 


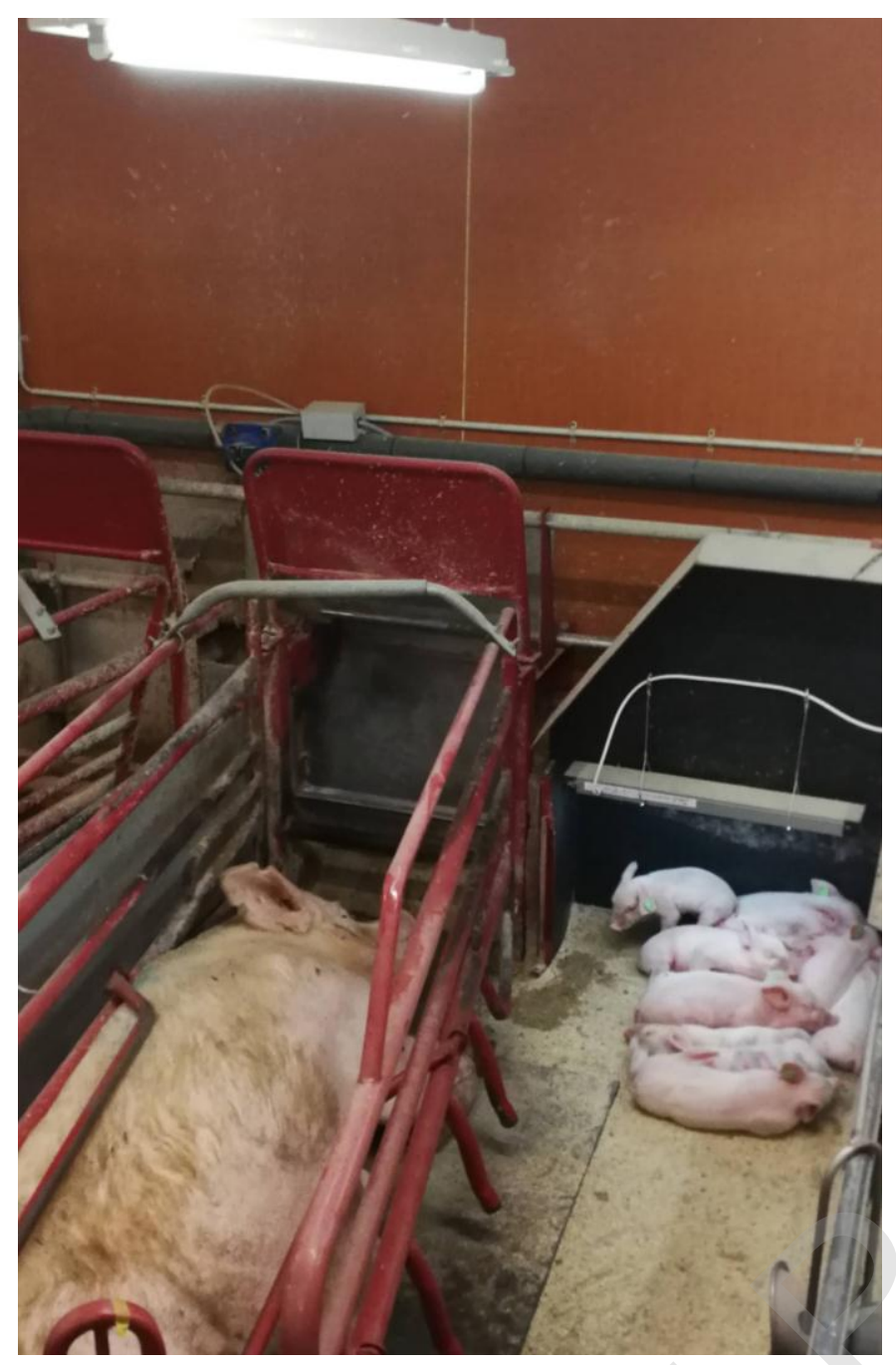

Fig 1. UVB light placed above the sow and above the piglet nest in the corner of the pen.

\subsubsection{UVB dose measurement}

A full spectrum of the irradiance was recorded for one tube, scanning from 200 to $700 \mathrm{~nm}$, with $1 \mathrm{~nm}$ increments (EOP146 detector probe, Instrument Systems-CAS140CT) at DTU Fotonik, Denmark. These data combined with the erythema reference action spectrum[16] enabled us to estimate the duration of UVB light required to achieve daily dose of $0.7 \mathrm{SED}$ and 1.0 SED for the two treatment groups. For these estimations, it was assumed that a piglet remaining directly under the lamp for 6 hours would receive a maximum of either 0.7 SED or 1.0 SED. This was done to minimize the risk of pigs developing erythema in response to overexposure of UVB light. The calculation of UVB exposure for sows was based on the assumption that they would be standing for $25 \%$ of the time and lying for $75 \%$ of the time. 
A handheld UVB meter (ILT 1400-BL photometer equipped with a SEL005/TLS312/TD detector, International Light Technologies, Peabody, MA, USA) was used to test the difference in UVB exposure between each of the 10 lamps used for the sows in order to allocate the correct height, and to adjust the dimmer for the piglets. This was also used to check the UVB exposure once during the trial.

\subsection{Sampling of blood}

Blood was sampled from sows and piglets on day 1, 12 and 24. For the piglets, blood sampling was performed by puncturing the jugular vein using a needle of 22G ( BD ref 360210, Becton Dickinson, Franklin Lakes, New Jersey, United States) or 21G (BD ref 360212) and $4 \mathrm{~mL}$ dry tubes (BD ref 368975) with a vacutainer holder. The procedure for the sows was identical, but the needle used was 18Gx1.5 (BD ref 360748). Piglets were manually restrained during blood sampling and sows were restrained using a snout snare. Immediately after blood collection, the tube was placed at room temperature for $30 \mathrm{~min}$ to coagulate. Stored at $5{ }^{\circ} \mathrm{C}$, and within 48 hours centrifuged for 15 minutes at $2500 \mathrm{~g}$ (Sigma 4K15 Centrifuge, Sigma Laborzentrifuge GmbH, Osterrode am Harz, Germany. Serum stored at $-80^{\circ} \mathrm{C}$ until analyses within 1 month.

\subsection{Sampling of feed}

Feed was sampled twice during the trial. Sampling was done in one of the pens where the included sows were kept. Samples were obtained from the pipe that supplied the sow with liquid feed. A plastic bag was placed under the pipe at the time of feeding and was immediately sealed after filling and placed in a freezer at $-18^{\circ} \mathrm{C}$. When it had frozen solid, the sample was transported in a cooler bag to the laboratory where it was stored at $-18^{\circ} \mathrm{C}$ until analysis.

\subsection{Analytical methods}

\subsubsection{Weighing}

Piglet weight was recorded on day 1 and 24 . Weights on day 1 were recorded using a handheld Ryom digital scale (Center-Gros A/S, Denmark) ranging from $100 \mathrm{~g}$ to $40 \mathrm{~kg}$ with $10 \mathrm{~g}$ intervals. Weights on day 24 were recorded using a Diesella table scale (Diesella A/S, Denmark) ranging from $100 \mathrm{~g}$ to $30 \mathrm{~kg}$ and with $5 \mathrm{~g}$ intervals. Piglets were placed in a bucket when weighed. 


\subsubsection{Vitamin D}

Blood samples were analyzed using a previously described method [19]. In short, the protein in $100 \mu \mathrm{L}$ of serum was precipitated by acetonitrile and cleaned up by solid-phase extraction, followed by derivatization by 4-phenyl-1,2,4-triazoline-3,5-dione, and quantification of $25(\mathrm{OH}) \mathrm{D}_{3}$ and vitamin $\mathrm{D}_{3}$ by liquid chromatography coupled with tandem mass spectrometry. The precision of the method was $<6 \%$ for both metabolites estimated from an in-house serum reference $(n=35)$.

\section{Statistical analysis}

The statistical software Rstudio (Rstudio, Inc., Boston) was used to perform all statistical analysis. A linear mixed model for $25(\mathrm{OH}) \mathrm{D}_{3}$ and vitamin $\mathrm{D}_{3}$ with group, parity and birthweight as fixed effects and sow as a random effect was fit using analysis of variance (ANOVA) with Tukey's test. Analysis of other parameters including sex, mortality and birthweight was performed using ANOVA and Tukey's test. Birthweight was grouped in to one of three groups: "Small" $(\mathrm{n}=10)$ referring to piglets <900 grams, "Medium" (n=131) was $1,400$ grams $>$ piglets $\geq 900$ grams and "Large" ( $n=54)$ described piglets $\geq 1,400$ grams. Results are given as mean \pm standard deviation $(\mathrm{SD})$.

\subsection{Results}

None of the pigs developed erythema during the trial.

\subsection{Sows}

The parity of the sows included in the trial ranged from 2-5 and the sows had no health issues prior to farrowing. After farrowing, 11 of the 15 sows received antibiotic treatment for MMA (Mastitis, Metritis, Agalactia). The four sows that did not receive treatment belong to one in the control, two in the $0.7 \mathrm{SED}$, and one in the 1.0 SED group.

Serum values for $25(\mathrm{OH}) \mathrm{D}_{3}$ and vitamin $\mathrm{D}_{3}$ for sows on all sampling days can be found in Table 1 . Vitamin D levels in serum of the sows showed no significant difference in $25(\mathrm{OH}) \mathrm{D}_{3}$ or vitamin $\mathrm{D}_{3}$ on day 1 . However, 
on day 12 and day 24 , a significant increase in $25(\mathrm{OH}) \mathrm{D}_{3}$ and vitamin $\mathrm{D}_{3}$ for the UVB-treated groups compared to the control.

Table 1. Results for $25(\mathrm{OH}) \mathrm{D}_{3}$ and vitamin $\mathrm{D}_{3}$ in serum $(\mathrm{ng} / \mathrm{mL})$ from sows

\begin{tabular}{llllllll}
\hline & & \multicolumn{2}{c}{ Control } & 0.7 SED & \multicolumn{1}{c}{1.0 SED } \\
& & mean & SD & Mean & SD & Mean & SD \\
\hline Day 1 & & & & & & & \\
& $25(\mathrm{OH}) \mathrm{D}_{3}$ & 15.1 & 3.7 & 16.3 & 3.4 & 16.4 & 2.8 \\
& ${\text { Vitamin } \mathrm{D}_{3}}$ & 2.92 & 0.72 & 3.29 & 0.50 & 2.95 & 1.23
\end{tabular}

Day 12

Day 24

$\begin{array}{lllllll}25(\mathrm{OH}) \mathrm{D}_{3} & 20.6^{\mathrm{a}} & 3.5 & 35.7^{\mathrm{b}} & 6.5 & 33.3^{\mathrm{b}} & 6.5 \\ {\text { Vitamin } \mathrm{D}_{3}}^{5.23^{\mathrm{a}}} & 1.24 & 22.4^{\mathrm{b}} & 3.41 & 23.12^{\mathrm{b}} & 5.00\end{array}$

$\begin{array}{lllllll}25(\mathrm{OH}) \mathrm{D}_{3} & 25.6^{\mathrm{a}} & 5.5 & 66.7^{\mathrm{b}} & 13.5 & 66.9^{\mathrm{b}} & 15.0\end{array}$

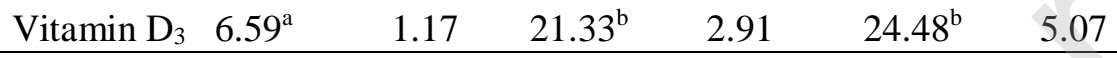

$\overline{a, b}$ Mean values with different superscript letters within a row were significantly different $(p<0.001)$

\subsection{Piglets}

\subsubsection{Sex, mortality and weight gain}

Each of the 15 sows kept 13 piglets. Information about the 195 piglets are given in Table 2. Piglets under 900 $\mathrm{g}$ were included in three of the litters in order to include 13 piglets from each litter. Of the piglets under 900 $\mathrm{g}$, six were from a sow in the control group (range: 720-895 g), one piglet weighing $855 \mathrm{~g}$ was from a sow in the 0.7 SED group, and three from a sow in the 1.0 SED group (range: 780-890). One piglet was excluded prior to random selection due to a birth defect; the remaining excluded piglets were excluded due to their size or through random selection.

Table 2: The distribution of sex, mortality and excluded piglets, percentage in brackets. Mean and SD for birthweight and weaning weight

\begin{tabular}{llllll}
\hline & & Control & 0.7 SED & 1.0 SED & All \\
\hline Sex & M (\%) & $30(46)$ & $27(42)$ & $32(49)$ & $89(46)$ \\
& F $(\%)$ & $35(54)$ & $38(58)$ & $33(51)$ & $106(54)$ \\
Mortality & $\mathrm{n}(\%)$ & $3(5)$ & $1(2)$ & $6(9)$ & $10(5)$
\end{tabular}




\begin{tabular}{llllll} 
Excluded piglets $^{1}$ & & & & & \\
Birthweight & $\mathrm{n}(\%)$ & $3(5)$ & $0(0)$ & $5(8)$ & $8(4)$ \\
& & & & & \\
& Mean, g & 1,390 & 1,156 & 1,198 & 1,248 \\
Weaning weight & SD, g & 392 & 216 & 264 & 315 \\
& & & & & \\
& Mean, g & 6,833 & 6,022 & 5,870 & 6,246 \\
& SD, g & 1,618 & 1,398 & 1,722 & 1,622 \\
\hline
\end{tabular}

${ }^{1}$ Due to unthriftiness

More females than males were included in the study ( $54 \%$ vs. $46 \%$ ), but no significant difference for serum $25(\mathrm{OH}) \mathrm{D}_{3}$, serum vitamin $\mathrm{D}_{3}$ or weight between gender were observed. Sows and their offspring being allocated a group before farrowing did not allow adjusting the groups according to birthweight. The control group had an average birthweight that was significantly higher $(\mathrm{p}<0.001)$ than both of the groups receiving UVB light. A mixed linear model including group, parity and sex as fixed effects and sow as a random effect found no significant difference in birthweight between the groups. When including birthweight in the model, no significant difference in weight on day 24 was found between groups. Categorizing the piglet in to three groups based on birthweight, "Small", "Medium" and "High", show a significant difference in weight on day 24 between the group "Large" and each of the two other groups $(\mathrm{p}<0.01)$. No significant difference in weight on day 24 was seen between the groups "Small" and "Medium".

\subsubsection{Vitamin D in serum}

Table 3 shows the results relating to $25(\mathrm{OH}) \mathrm{D}_{3}$ in serum i.e. vitamin $\mathrm{D}$ status and for vitamin $\mathrm{D}_{3}$ in serum. On day 1 , neither for vitamin $\mathrm{D}$ status nor vitamin $\mathrm{D}_{3}$ in serum a significant difference was found between the groups, showing an overall mean for vitamin D status of $0.96 \pm 0.19 \mathrm{ng} / \mathrm{mL}$. On day 12 and 24 , a significant difference was seen between the control group and each of the two UVB-treatments i.e. 0.7 SED and 1.0 SED $(\mathrm{p}<0.001)$ for vitamin D status as well as for vitamin D3 in serum. The UVB light significantly increased the vitamin D levels in piglets compared to the unexposed control group, but no significant difference was observed between the two treatment groups.

Table 3. Results for $25(\mathrm{OH}) \mathrm{D}_{3}$ and vitamin $\mathrm{D}_{3}$ in serum $(\mathrm{ng} / \mathrm{mL})$ from piglets

Control $\quad 0.7 \mathrm{SED} \quad 1.0 \mathrm{SED}$




\begin{tabular}{llllllll} 
& & Mean & SD & Mean & SD & Mean & SD \\
\hline Day 1 & & & & & & & \\
& $25(\mathrm{OH}) \mathrm{D}_{3}$ & 0.93 & 0.28 & 1.00 & 0.27 & 0.94 & 0.22 \\
& Vitamin $\mathrm{D}_{3}$ & 0.06 & 0.03 & 0.07 & 0.04 & 0.04 & 0.03 \\
Day 12 & & & & & & & \\
& $25(\mathrm{OH}) \mathrm{D}_{3}$ & $4.10^{\mathrm{a}}$ & 1.23 & $12.95^{\mathrm{b}}$ & 2.41 & $12.9^{\mathrm{b}}$ & 3.65 \\
& Vitamin $\mathrm{D}_{3}$ & $0.47^{\mathrm{a}}$ & 0.46 & $8.21^{\mathrm{b}}$ & 2.32 & $8.44^{\mathrm{b}}$ & 3.51 \\
Day 24 & & & & & & & \\
& $25(\mathrm{OH}) \mathrm{D}_{3}$ & 5.54 & 1.97 & $21.6^{\mathrm{b}}$ & 3.97 & $19.5^{\mathrm{b}}$ & 6.14 \\
& ${\text { Vitamin } \mathrm{D}_{3}}$ & $0.36^{\mathrm{a}}$ & 0.23 & $8.25^{\mathrm{b}}$ & 2.50 & $7.61^{\mathrm{b}}$ & 3.40 \\
\hline
\end{tabular}

$\overline{a, b}$ Mean values with different superscript letters within a row were significantly different $(p<0.001)$

\section{Discussion}

This is the first study to investigate the effect of UVB light on vitamin D status in sows and piglets.

The UVB light tubes worked well and no adverse effect (erythema) was observed in the skin of exposed animals. During the experiment, setting up the lights presented some challenges. The lights above the piglet nests were slightly movable, and when the piglets had grown, they were able to manipulate and move the lights around. Also, the piglets were able to move freely around the entire pen, and on some days, the floor in some of the piglet nests became soiled. As a result, the piglets preferred to remain in other parts of the pen outside the range of the UVB light tubes. This meant that the assumption that piglets would stay 6 hours under the tubes and thereby receive of a daily dose of 0.7 SED or 1.0 SED was not met for these piglets. The sows were housed in farrowing crates and therefore remained under the UVB tubes for the entire exposure time. However, we could not ascertain whether the estimation of $75 \%$ standing and $25 \%$ lying time was met.

Even though the UVB-dose did not reach the intended dose for piglets, the results showed a significant difference in vitamin D status on day 12 and 24 between the groups that received UVB light and the control group, for both sows and piglets. We did not, however, find any significant difference between the 0.7 SED group and the 1.0 SED group, as previously reported for slaughter pigs by Barnkob et al.[19]. In our study, the dose was controlled by adjusting the irradiance and the height of UVB tubes, but the duration of exposure was fixed. In the study by Barnkob et al. [19], the dose was controlled by adjusting the duration of exposure, with a fixed irradiance and height. This suggests that having a fixed height and irradiance but variable duration is a 
better way to adjust the dose in an experimental setup. These results are encouraging for further studies on enhancing vitamin D levels using UVB light.

Among domestic farm animals tested, pigs are born with the lowest vitamin D status, which may predispose to neonatal rickets [21]. We report levels for vitamin D status in newborn piglets at $1 \mathrm{ng} 25(\mathrm{OH}) \mathrm{D}_{3} / \mathrm{mL}$ serum, which is even lower than previously reported at $2.5-5.5 \mathrm{ng} / \mathrm{ml}$ serum [22,23]. In the present study the sows were followed from farrowing until weaning and thus no analysis on the vitamin D status of feed during gestation were performed. However, the gestation feed was supplemented with vitamin D at a level of 800 IU/kg feed according to Danish recommendation standards [5]. No reference values for adequate vitamin D status for pigs are available. If adequate vitamin D status are considered similar for pigs and for humans, then the newborn piglets would be categorized as vitamin D deficient [6] a condition that may lead to retarded skeletal growth and reduced weight gain. This might indicate that sows supplementation with vitamin D during pregnancy had been insufficient.

At weaning, the vitamin D status of the piglets in the UVB-treated groups would in humans be considered sufficient ( $\geq 20 \mathrm{ng} / \mathrm{mL}$ ), while the piglets in control group would be described as deficient $(<12 \mathrm{ng} / \mathrm{mL})$ [6]. The vitamin D source for piglets was apart from the milk and feed provided from day 2 and day 7, respectively, sows milk. The vitamin D intake from the sows milk is difficult to estimate partly because of the individual level of content of vitamin in sows milk and the variation of milk uptake from individual piglets [24]. Levels of vitamin $\mathrm{D}$ in sows milk has been reported to be approximately $2 \mathrm{ng}$ vitamin $\mathrm{D}_{3} / \mathrm{g}$ and $5 \mathrm{ng} 25(\mathrm{OH}) \mathrm{D}_{3} / \mathrm{g}$ in some studies $[15,25]$. The result for the control group indicate that this vitamin supply do not ensure an adequate vitamin $\mathrm{D}$ status for the piglets. The vitamin $\mathrm{D}$ status of the sows at parturition should be seen as the lowest levels occurring during their reproduction cycle due to both placental transfer to the fetuses as well as the increased demand in the calcium metabolism after parturition $[15,26]$. This study showed that UVB exposure of sows for 22 days resulted in vitamin D levels comparable to those ( $53 \mathrm{ng} / \mathrm{mL})$ that previously has been shown to increase birthweight of piglets $[9,15]$.

No significant difference in weight gain was found between treatment groups. However, the study was not designed to detect small improvements in daily weight gain and therefore does not exclude such effects. Other studies have shown an increase in growth rate for piglets following a single oral dose of vitamin D at farrowing 
[8]. Also the present study was not designed to test if UVB exposure of the pregnant would improve farrowing results.

The advantage of UVB light as the source of vitamin D seems to be the strategy, which can ensure a sufficient vitamin D status at an earlier stage than through feeding for the piglets. Piglet will start to eat creep feed only at day 10-21. In our study the piglets in the control group could be categorized as deficient at weaning. The piglets in UVB-treated groups at day 12 were not deficient but had an inadequate vitamin D status, while at weaning the piglets could be categorized as having a sufficient vitamin D status. Further studies including a greater number of sows and piglets are currently planned, in order to determine the effects of the increased vitamin D status achieved by UVB-exposure, on sow reproduction and average daily weight gain in piglets.

\section{Conclusion}

Sows and their newborn piglets exposed for 24 days to a daily dose of UVB light to a maximum of 0.7 SED or 1.0 SED had a significantly higher vitamin D status and level of vitamin $\mathrm{D}_{3}$ in serum compared to a control group. This study showed no significant difference in vitamin D levels between the groups receiving 0.7 SED and 1.0 SED. Vitamin D status in newborn piglets at $1 \mathrm{ng} 25(\mathrm{OH}) \mathrm{D}_{3} / \mathrm{mL}$ serum, would in humans be catergorized as deficient. At weaning, the vitamin D status of the piglets in the UVB-treated groups would be caterorized as sufficient, while the piglets in control group would be described as deficient. Further studies including a greater number of pigs are currently planned, since several other studies have shown an effect on average daily weight gain in piglets when either the sows or the piglets received extra vitamin D.

\section{Author statement.}

Sine Stricker Jakobsen: Methodology, Investigation, Formal Analysis, Writing - Original Draft. Jens Peter Nielsen: Conceptualization, Methodology, Writing - Review \& Editing, Supervision, Funding Acquisition. Jette Jakobsen: Conceptualization, Methodology, Writing - Review \& Editing, Supervision, Project 
administration, Funding Acquisition.

\section{Author contributions}

SSJ: Methodology, Investigation, Formal Analysis, Writing - Original Draft. JPN:

Conceptualization, Methodology, Writing - Review \& Editing, Supervision, Funding Acquisition.

JJ: Conceptualization, Methodology, Writing - Review \& Editing, Supervision, Project administration, Funding Acquisition.

\section{Funding}

GUDP under The Ministry of Environment and Food of Denmark funded this project. GUDP were not involved in study design, data collection, analysis and interpretation, writing of the report and decision to submit this article.

\section{Conflict of interest}

Authors of this paper have no conflict of interest.

\section{Acknowledgements}

The authors are grateful to: Kyra Drechsler, for measurements relating to the UVB lights, and skilful analyses of the serum and feed for vitamin D metabolites. Rasmus Syhler, for assisting in on-farm weight recording and blood sampling on farm. Jens Nørgaard, DVM, for assisting in weight recording and blood sampling on farm. Staff at Kongsdal multi, for care taking of the animals and for letting us disturb their daily work routines for an entire month. Dennis Dan Corell, DTU Fotonik, for performing the UVB-spectral measurements, and Photocat Aps, for mounting the dimmer to the UVB-light. Dan Børge Jensen for statistical consultancy.

\section{References}

[1] C. Palacios, L. Gonzalez, Is vitamin D deficiency a major global public health problem?, J. Steroid Biochem. Mol. Biol. 144 (2014) 138-145. doi:10.1016/j.jsbmb.2013.11.003.

[2] M.F. Holick, T.C. Chen, Vitamin D defciency: a worldwide problem with health consequences, Am. J. Clin. Nutr. 87 (2008) 1080S-6S. doi:87/4/1080S [pii]. 
[3] E. Comission, COMMISSION DIRECTIVE of 12 April 1991 amending the Annexes to Council Directive 70/524/EEC concerning additives in feedingstuffs, (1991).

[4] EUR-Lex (2009) Commission Regulation (EC) No 887/2009. http://eurlex.europa.eu/LexUriServ/LexUriServ.do?uri=OJ:L:2009:254:0068:0070:EN:PDF（accessed 29 November 2019).

[5] P. Tybirk, N.M. Sloth, N. Kjeldsen, L. Shooter, Normer for næringsstoffer, (2018) 1-14.

[6] A.C. Ross, Institute of Medicine (U.S.). Committee to Review Dietary Reference Intakes for Vitamin D and Calcium., DRI, Dietary Reference Intakes : Calcium, Vitamin D, National Academies Press, 2011.

[7] Y. Zhao, B. Yu, X. Mao, J. He, Z. Huang, P. Zheng, J. Yu, G. Han, X. Liang, D. Chen, Dietary vitamin D supplementation attenuates immune responses of pigs challenged with rotavirus potentially through the retinoic acid-inducible gene i signalling pathway, Br. J. Nutr. 112 (2014) 381-389. doi:10.1017/S000711451400097X.

[8] S.J.P. Tousignant, Effect of oral vitamin D3 supplementation on growth and serum 25-hydroxy vitamin D levels of pigs up to 7 weeks of age, J. Swine Heal. Prod. 21 (2013) 94-98.

[9] G. Sørensen, M. Friis, Hy-D i sofoder øger kuldvægten vedfravænning med 3,6 kg, (2016) 1-14.

[10] J.D. Coffey, E.A. Hines, J.D. Starkey, C.W. Starkey, T.K. Chung, Feeding 25-hydroxycholecalciferol improves gilt reproductive performance and fetal vitamin D status, J. Anim. Sci. 90 (2012) 3783-3788. doi:10.2527/jas.2011-5023.

[11] J. Quarterman, A.C. Dalgarno, A. Adam, B.F. Fell, R. Boyne, The distribution of vitamin D between the blood and the liver in the pig, and observations on the pathology of vitamin D toxicity, Br. J. Nutr. (1964).

[12] C.N. Chineme, L. Krook, W.G. Pond, Bone pathology in hypervitaminosis D an experimental study in young pigs, Cornell Vet. (1976).

[13] J. Wimsatt, S.L. Marks, T.W. Campbell, J.D. Johnson, R.F. Nachreiner, Dietary vitamin D toxicity in a household of pot-bellied pigs (Sus scrofa)., J. Vet. Intern. Med. 12 (1998) 42-44. doi:10.1111/j.19391676.1998.tb00495.x. 
[14] W.M. Haschek, L. Krook, F.A. Kallfelz, W.G. Pond, Vitamin D toxicity. Initial site and mode of action., Cornell Vet. 68 (1978) 324-364.

[15] G.M. Weber, A.K.M. Witschi, C. Wenk, H. Martens, Triennial growth symposium-effects of dietary 25-hydroxycholecalciferol and cholecalciferol on blood vitamin D and mineral status, bone turnover,

[16] Scientific committee on consumer products (SCCP), Opinion on Biological effects of ultraviolet radiation relevant to health with particular reference to sunbeds for cosmetic purposes, 2006.

[17] M.F. Holick, A.R. Webb, B.R. DeCosta, Sunlight Regulates the Cutaneous Production of Vitamin D3 by Causing Its Photodegradation, J. Clin. Endocrinol. Metab. 68 (1989) 882-887.

[18] J. MacLaughlin, R. Anderson, M.F. Holick, Spectral character of sunlight modulates photosynthesis of previtamin D3 and its photoisomers in human skin, Science (80-. ). 12 (1982) 121-124.

[19] L.L. Barnkob, P.M. Petersen, J.P. Nielsen, J. Jakobsen, Vitamin D enhanced pork from pigs exposed to artificial UVB light in indoor facilities, Eur. Food Res. Technol. 245 (2019) 411-418. doi:10.1007/s00217-018-3173-6.

[20] M.K.B. Bogh, A.V. Schmedes, P.A. Philipsen, E. Thieden, H.C. Wulf. A small suberythemal ultraviolet B dose every second week is sufficient to maintain summer vitamin D levels: a randomized controlled trial. Br J Dermatol, 166 (2012) 430-433.

[21] C. Lauridsen, S.K. Jensen. Vitamin Nutrition. Nutritional Physiology of Pigs, 2013 1-28. https://pure.au.dk/ws/files/69481636/Chapter_12_Vitamin_nutrition.pdf (accessed 29 November 2019)

[22] M.D. Lindemann, H.J. Monegue, Y.D. Jang, Vitamin D Status of Pigs from Birth to Weaning as Affected by Gavage or Injection, 2008 (n.d.) 59-65.

[23] J.P. Goff, R.L. Horst, E.T. Littledike, Effect of sow vitamin D status at parturition on the vitamin D status of neonatal piglets, J. Nutr. 114 (1984) 163-169. doi:10.1093/jn/114.1.163.

[24] A.V. Hansen, A.B. Strathe, E. Kebreab, J. France, P.K. Theil. Predicting milk yield and composition in lactating sows: A Bayesian Approach. J Anim Sci. 90 (2012) 2285-98. doi: 10.2527/jas.2011-4788. Epub 2012 Feb 3

[25] J.R. Flohr, M.D. Tokach, S.S. Dritz, J.M. DeRouchey, R.D. Goodband, J.L. Nelssen, J.R. Bergstrom, 
An evaluation of the effects of added vitamin D3 in maternal diets on sow and pig performance1,2, J. Anim. Sci. 92 (2014) 594-603. doi:10.2527/jas2013-6792.

[26] C.S. Kovacs. Vitamin D in pregnancy and lactation: maternal, fetal, and neonatal outcomes from human and animal studies. Am J Clin Nutr. 88(suppl) (2008) 520S-8S. 